\title{
Distribution of Pathologic Smear Results and Histopathologic Agreement in Precancerous Cervical Lesions
}

\section{Eser COLAK ${ }^{1}$, Esra Zeynep COSKUNOGLU²}

Konya, Turkey

\begin{abstract}
OBJECTIVES: The accuracy of the Papanicolau smear test is very important in cervical cancer which is preventable cancer. In this study, we aimed to investigate the distribution of smear results and cytohistopathological correlation and agreement in biopsies.

STUDY DESIGN: A retrospective study was performed at the gynecology obstetrics and pathology department of Baskent University Konya Application and Research Hospital, over a 5-year period. The histopathology results of 89 patients who underwent colposcopic biopsy from 273 patients with pathologic Pap smear results were examined. The histopathologic results and pathologic Pap smear results were compared and the compatibility between them was examined.
\end{abstract}

RESULTS: Data records were collected for 11,191 women. Overall, the prevalence of cytologic abnormalities was $2.43 \%$. The cytohistopathologic correlation in epithelial lesions was $56 \%$ and was statistically significant. In glandular lesions, normal biopsy results were reported in 93\% of AGC-NOS cytology results, whereas there was a 100\% malignancy correlation with AGC-FN cytology results. In terms of detecting low and high-grade lesions, the false-negative rate was $12 \%$ and the false-positive rate was $17 \%$.

CONCLUSION: In conclusion, Pap smears can be less cost-effective and easily accessible method. While conservative treatment is appropriate in young patients because of possible regression even in high-grade lesions; in older patients, it should not be hesitated to get biopsy when a suspicious clinic is present.

Keywords: Cervical biopsy, Cytology, Pap smear, Precancerous

Gynecol Obstet Reprod Med 2020;26(3):214-219

\section{Introduction}

Cervical cancer is one of the most common causes of death in women in developing countries (1). It is well known that screening for cervical cancer using Papanicolaou (Pap) smears significantly reduces the incidence of cervical cancer and as-

${ }^{1}$ Department of Gynecology and Obstetrics, Baskent University School of Medicine, Konya Medical and Research Center, Turkey

2 Department of Pathology, Baskent University School of Medicine, Konya Medical and Research Center, Turkey

Address of Correspondence: Eser Colak

Department of Gynecology and Obstetrics,

Baskent University School of Medicine,

Medical and Research Center, 42080 Selcuklu,

Konya Turkey

dresercolak@hotmail.com

Submitted for Publication: $\quad$ 10.07.2019

Revised for Publication: $\quad 06.11 .2019$

Accepted for Publication: $\quad 29.10 .2019$

ORCID IDs of the authors: $\quad$ EC: 0000-0002-8184-7531,

EZC: $0000-0002-6176-7016$

\begin{tabular}{|c|c|}
\hline \multirow{3}{*}{ 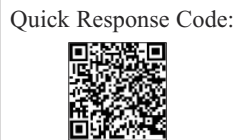 } & Access this article online \\
\hline & $\begin{array}{l}\text { Website: www.gorm.com.tr } \\
\text { e- mail: info@gorm.com.tr }\end{array}$ \\
\hline & DOI:10.21613/GORM.2020.1030 \\
\hline
\end{tabular}

How to cite this article: Colak E. Coskunoglu Z. Distribution of Pathologic Smear Results and Histopathologic Agreement in Precancerous Cervical Lesions. Gynecol Obstet Reprod Med. 2020;26(3):214-219 sociated death rates in developed countries. Cervical carcinoma remains a major health issue due to the lack of such programs in low-income countries. There are 493,000 new cases of cervical carcinoma diagnosed each year around the world, and 274,000 women die from this disease each year. About $85 \%$ of these cases occur in low-income countries, accounting for $15 \%$ of all cancers in women (2). The most cost-effective screening method for cervical cancer is the Pap smear test (3), which was recently reported to have $55.4 \%$ sensitivity and 96.8\% specificity. Abnormal Pap smear results constitute indications for endocervical curettage, colposcopy, and cervical biopsy (4).

The 2001 Bethesda System is the most commonly used and most widely accepted classification for reporting cervical smear samples. In the Bethesda System, squamous epithelial cell abnormality is divided into five categories including atypical squamous cells of undetermined significance (ASC-US), atypical squamous cells-cannot exclude high-grade squamous intraepithelial lesion (HSIL) (ASC-H), the low-grade squamous intraepithelial lesion (LSIL), HSIL, and squamous cell carcinoma (SCC). On the other hand, glandular epithelial abnormalities are divided into three categories including atypical glandular cells not otherwise specified (AGC), endocervical in 
situ adenocarcinoma (AIS), and adenocarcinoma (endocervical, endometrial, extrauterine and nonspecified) (5).

Cervical carcinomas are preventable conditions. Pap smear cytology has been used for screening since 1943 (6). However, the best screening methods for cervical carcinomas still remain unclear. Different methods including simple cytology, Human papillomavirus (HPV) - DNA tests and cytology repeats have been reported in the literature (7). Cytologic screening methods are still not effectively used in developing countries. Although cytology is the most specific method for screening today, it can sometimes be insufficient for premalignant lesions (8). The evaluation of high-grade epithelial lesions through colposcopy and biopsy is a widely accepted practice. However, the management of low-grade lesions remains unclear and updates are being made regarding this issue. Follow-up of pathologic cytology results with Pap smears can sometimes create anxiety in patients and make it difficult to follow-up patients from rural areas. In these cases, patients can sometimes be referred for colposcopy and biopsy. High-grade premalignant lesions hidden under cytology can sometimes be detected using colposcopy and biopsy $(9,10)$. Nevertheless, patients may sometimes undergo unnecessary surgical intervention. In our study, we planned to examine the compatibility between pathologic Pap smear cytology results and histopathologic results collected using colposcopic biopsy, without HPV results.

\section{Material and Method}

After approved by the Institutional Review Board of Baskent University (KA19/303), 11,199 Pap smear results of patients admitted to Baskent University Konya Application and Research Hospital obstetrics and gynecology outpatient clinic between January 1 ${ }^{\text {st }}, 2013$ and December 31 ${ }^{\text {st }}, 2017$ were retrospectively analyzed. The histopathology results of 89 patients who underwent colposcopic biopsy from 273 patients with pathologic Pap smear results were examined. The remaining 184 patients were those who did not undergo biopsy and did not have a regular follow-up. Eighty-nine histopathologic results were compared with the pathological Pap smear results from the same patient. The histopathologic results and pathologic Pap smear results of 89 patients were compared and the compatibility between them was examined.

Among the patients admitted to our hospital outpatient clinics, cervical Pap smear tests were recommended for patients who were aged older than 21 years. Cervical smear tests were performed in patients who responded positively to this recommendation. Before the collection of materials, obstetric and gynecologic anamneses of patients were taken and bimanual examinations were performed after cervical samples were taken. In our clinic, examinations of patients who were not suitable for site sampling due to anamnesis (bleeding, vaginal medication use, recent coitus) were postponed.
Cervical cytology samples were taken by placing a smear brush on the external cervical os and turning 360 degrees clockwise. The removed cells were fixed on the slide using a smear brush and placed in closed boxes. Smears were sent to the pathology department where the slides were stained using the Papanicolau method for cytopathologic evaluation. The results were classified according to the Bethesda system. A colposcopic biopsy was only performed in patients with pathologic Pap smear results; endocervical curettage (ECC) was added in patients with glandular lesions. In patients with abnormal cytology who underwent biopsy, the biopsy specimens were fixed in neutral buffered formalin solution and were transferred to the Pathology Department immediately after the colposcopic biopsy sampling where they were processed to create paraffin-embedded tissue sections. The sections were then stained using a routine hematoxylin-eosin staining method.

The test results (Pap smear and biopsy) are categorical. Therefore, frequencies, percentages and cross tables were used for all evaluations of categorical variables. The correlations between the two tests were analyzed by Gamma statistics via crosstables. If the p-value is lower than 0.05 , then the statistical result is evaluated as significant. All analyses were done by SPSS 22.0 (Statistical Package for Social Science).

\section{Results}

Data records were collected for 11.191 women. Overall, the prevalence of cytologic abnormalities was $2.43 \%$, and the prevalence of ASC-US, ASC-H, LSIL, HSIL, AGC-NOS, and AGC- FN was $1.58 \%, 0.10 \%, 0.2 \%, 0.12 \%, 0.32$, and 0.03 respectively. The prevalence of preinvasive cervical neoplasia was $2.35 \%$, and the prevalence of invasive neoplasia was $0.05 \%$. The rate of patients with 'insufficient material' as a result was $1.70 \%$ (Table I).

In patients with a cytology result of ASCUS, the rates of normal, LGSIL, HGSIL, and SCC results were $74.4 \%, 12.8 \%$, $10.3 \%$, and $2.6 \%$, respectively in the colposcopic biopsy. In patients with a cytology result of LGSIL, the rates of normal, LGSIL, and HGSIL results were $46.2 \%, 23.1 \%$, and $30.8 \%$, respectively in the colposcopic biopsy. In patients with a cytology result of HGSIL, the rates of normal, low and highgrade lesion results were $11.1 \%, 66.7 \%$, and $22.2 \%$, respectively, in the colposcopic biopsy. In patients with a cytology result of ASC-H in which HGSIL was not ruled out, the rates of normal and preinvasive results were $40 \%$ and $60 \%$, respectively, in colposcopic biopsy (Table II). The cyto-histopathologic correlation in epithelial lesions was $56 \%$ and was statistically significant $(p<0.001)$. In glandular lesions, normal biopsy results were reported in $93 \%$ of AGC-NOS cytology results, whereas there was a $100 \%$ malignancy correlation with AGC-FN cytology results (Table III). 
Table I: Distribution of cervical cytological abnormalities

\begin{tabular}{|c|c|c|c|c|c|c|}
\hline & \multicolumn{3}{|c|}{ Frequency } & \multicolumn{2}{|l|}{ Percent } & $\begin{array}{c}\text { Total Smear \% } \\
n=11,199\end{array}$ \\
\hline Insufficient material & \multicolumn{3}{|c|}{191} & \multicolumn{2}{|l|}{----- } & 1.70 \\
\hline ASC-US & \multicolumn{3}{|c|}{178} & \multicolumn{2}{|l|}{65.2} & 1.58 \\
\hline ASC-H & \multicolumn{3}{|c|}{12} & \multicolumn{2}{|l|}{4.4} & 0.10 \\
\hline LSIL & \multicolumn{3}{|c|}{23} & \multicolumn{2}{|l|}{8.4} & 0.20 \\
\hline HSIL & \multicolumn{3}{|c|}{14} & \multicolumn{2}{|l|}{5.1} & 0.12 \\
\hline SCC & \multicolumn{3}{|c|}{6} & \multicolumn{2}{|l|}{2.2} & 0.05 \\
\hline AGC-NOS & \multicolumn{3}{|c|}{36} & \multicolumn{2}{|l|}{13.2} & 0.32 \\
\hline AGC-FN & \multicolumn{3}{|c|}{4} & \multicolumn{2}{|l|}{1.5} & 0.03 \\
\hline Total & \multicolumn{3}{|c|}{273} & \multicolumn{2}{|l|}{100.0} & 2.43 \\
\hline \multicolumn{7}{|c|}{$\begin{array}{l}\text { ASC-US: Atypical Squamous Cells of Undetermined Significance, ASC-H: Atypical squamous cells - cannot exclude HSIL, LSIL: Low grade squa- } \\
\text { mous intraepithelial lesion, HSIL: High grade squamous intraepithelial lesion, SCC: Squamous cell carcinoma, AGC: Atypical glandular cells, AGC- } \\
\text { NOS: AGC not otherwise specified, AGC-FN: AGC favor neoplasia }\end{array}$} \\
\hline Pap Smear & $\mathrm{n}$ & & LSIL & HSIL & SCC & Total \\
\hline \multirow{2}{*}{ ASC-US } & 29 & & 5 & 4 & 1 & 39 \\
\hline & $74.4 \%$ & & $12.8 \%$ & $10.3 \%$ & $2.6 \%$ & $100.0 \%$ \\
\hline \multirow{2}{*}{ LSIL } & 6 & & 3 & 4 & 0 & 13 \\
\hline & $46.2 \%$ & & $23.1 \%$ & $30.8 \%$ & $0 \%$ & $100.0 \%$ \\
\hline HCU & 1 & & 6 & 2 & 0 & 9 \\
\hline ПSIL & $11.1 \%$ & & $66.7 \%$ & $22.2 \%$ & $0 \%$ & $100.0 \%$ \\
\hline $\mathrm{ASC}-\mathrm{H}$ & 2 & & 2 & 1 & 0 & 5 \\
\hline וזע & $40.0 \%$ & & $40.0 \%$ & $20.0 \%$ & $0 \%$ & $100.0 \%$ \\
\hline 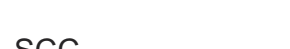 & 1 & & 0 & 0 & 4 & 5 \\
\hline sce & $20.0 \%$ & & $0 \%$ & $0 \%$ & $80.0 \%$ & $100.0 \%$ \\
\hline Total & 39 & & 16 & 11 & 5 & 71 \\
\hline Tutal & $54.0 \%$ & & $22.5 \%$ & $15.5 \%$ & $7.0 \%$ & $100.0 \%$ \\
\hline
\end{tabular}

Gamma $=0.562, p<0.001$. ASC-US: Atypical squamous cells of undetermined significance, ASC-H: Atypical squamous cells-cannot exclude, LSIL: Low grade squamous intraepithelial lesion, HSIL: High grade squamous intraepithelial lesion, SCC: Squamous cell carcinoma

Table III: Evaluation of histopathology results of the patients with abnormal pap smear-glandular cells

\begin{tabular}{llll}
\hline Pap Smear & $\mathrm{n}$ & Adeno-Ca & Total \\
\hline \multirow{2}{*}{ AGC-NOS } & 14 & 1 & 15 \\
& $93.3 \%$ & $6.7 \%$ & $100.0 \%$ \\
AGC-FN & 0 & 3 & 3 \\
& $0 \%$ & $100.0 \%$ & $100.0 \%$ \\
TOTAL & 14 & 4 & 18 \\
& $77.8 \%$ & $22.2 \%$ & $100.0 \%$ \\
\hline
\end{tabular}

Gamma $=1.000, p=0.019$. AGC: Atypical glandular cells, AGC-NOS: AGC not otherwise specified, AGC-FN: AGC favor neoplasia

\section{Discussion}

Cervical cancers that have a long preinvasive process can be prevented by screening before they become invasive. Although the prevalence of preinvasive lesions has increased compared with previous years, the frequency of invasive carcinomas has gradually decreased (11). The prevalence of cer- vical preinvasive and invasive lesions varies according to the patient population, race, and the experience of the pathologist. In a study with smear results from 33 centers, the prevalence of ASC-US, LSIL, HSIL, and AGC were reported as 1.07\%, $0.3 \%, 0.17 \%$, and $0.08 \%$, respectively (12). In our study, the prevalences of ASC-US, LSIL, HSIL, and AGC were 1.58\%, 
$0.2 \%, 0.12 \%$, and $0.35 \%$, respectively. The prevalence of pathologic smears was reported as $2.83 \%$ in the study conducted by Yalti et al. (13). The results of other studies showing the distribution of cytology results in our country were similar to the results of our study $(14,15)$. The prevalence of ASC-US, LSIL, HSIL, and AGC in the United States of America (USA) were reported as 3.9\%, 2.1\%, 0.5\%, and $0.2 \%$, respectively $(16,17)$. Although the results of our study are similar to those of other studies conducted in our country, they appear to be lower than the prevalence of studies conducted in the USA. This condition may be associated with the low prevalence of HPV infection shown in our country in previous studies $(18,19)$.

Some high-grade lesions are overlooked in Pap smear tests due to some limitations of cytology. It is important in patient follow-up to distinguish high-grade lesions (HGSIL, SCC, adenocarcinoma) that require advanced detailed surgery. In this study, we compared the cytology and histopathology results of the same patients and examined the correlation between them. In addition, we evaluated the false-negative and false-positive rates and the compatibility in smear results in terms of the detection of high-grade lesions. In our study, we observed a correlation with a rate of $56 \%$ cytohistopathologically in the detection of squamous cell lesions, whereas there was a correlation rate of $100 \%$ in the detection of glandular cell lesions. The biopsy results of 39 patients with ASCUS as a result of smear tests showed four HGSIL and one SCC. HGSIL was detected in four of the 13 patients who were reported as having LGSIL cytologically. We found a false-negative rate of about $12 \%$. Alwahaibi et al. reported a correlation with the rate of $62 \%$ cytohistopathologically in their study. That study showed a false-negative rate of $4.6 \%$ and a falsepositive rate of $32 \%$ (20). Cytohistopathologic correlations between $51 \%$ and $75 \%$ were reported in similar studies in the literature $(21,22)$. Of the 9 cytologically reported patients with HGSIL, one was evaluated as normal and six as LGSIL. Two of the five patients with ASC-H who were not discriminated from HGSIL were evaluated as normal, whereas the other two were evaluated as having LGSIL. Of the five patients with SCC, one was evaluated as normal and the biopsy of four patients was again determined as SCC. With these results, we can say that our false- positive rate of $17 \%$ was higher than our false-negative rate, and this was consistent with similar studies in the literature (20-22). According to our data, the Pap smear results were comparable with histopathology results or they showed higher grades than the biopsy results. The correlation of this condition was statistically significant. The higher false-positive rate was due to this correlation. The false-positive rate is expected to be higher than the false-negative rate so that patients with very high grades are not overlooked.

We had one patient with ASC-US cytology with a discordant SCC biopsy result. As ASC-US and SCC are on the far edges of squamous lesions, it is not likely to confuse one with others. When we checked patient data, we realized that the patient was diagnosed with SCC almost two years after the initial ASC-US diagnosis. Like all other patients with ASC-US cytology, this patient was also fully informed about the process, but she did not show up in follow-up appointments until she developed invasive cancer. We also had another extreme cytology - biopsy discordance. The smear was reported as SCC whereas the biopsy findings were benign. We think that the initial biopsy was sampled from uninvolved parts of the cervix. However, the repeat biopsy had never been performed as the patient refused to come. So, we made the data as it was without any changes.

According to the Bethesda system, the frequency of AGC varies between $0.1 \%$ and $2.1 \%$ in the literature $(23,24)$. In line with the literature, AGC was detected in approximately $0.35 \%$ of all cervical cytology in our study. In the literature, malignancy was reported in $22-50 \%$ of patients whose cytology was reported as AGC (25). Kim et al. found malignancy in $28 \%$ of patients with AGC cytology. The majority of these malignancies identified were cervical adenocarcinomas. Extragenital malignancies were also reported (26). Boyraz et al. reported malignancy with a rate of $33.8 \%$ (27). In our study, we found malignancy in $22.2 \%$ of patients with AGC cytology. All of these malignancies were reported as cervical adenocarcinoma. No endometrial extragenital malignancy was detected in our study. AGC causes many malignancies in women, the majority of which are cervical. However, the rates of malignancy-risk vary according to the types of AGC identified. Tam et al. reported malignancy rates of $67 \%$ in patients with AGC-FN cytology and 19\% in patients with AGCNOS cytology (28). Likewise, Sawangsang et al. reported a significantly higher rate of malignancy in patients with AGCFN cytology (29). Similarly, in our study, we found a significantly higher malignancy rate in patients with AGC-FN cytology. There are clinical trials that report that the major criterion that makes up the difference between AGC-NOS and AGC-FN is patient age (30,31).

In our study, we did not report specificity and sensitivity values because only biopsies were performed in patients with abnormal cytology. We were only able to detect false-negative and false-positive rates. We were also unable to include the patients' clinical findings in our study because the data were retrospectively accessed.

In conclusion, Pap smears can be a less cost-effective and easily accessible method. While conservative treatment is appropriate in young patients because of possible regression even in high-grade lesions; in older patients, it should not be hesitated to get biopsy when a suspicious clinic is present.

\author{
Acknowledgment \\ Conflict of interest: No actual or potential conflict of interest \\ in relation to this article exists. \\ Ethical approval: The study protocol was approved by the
}


Institutional Review Board of Baskent University (KA19/303) and was performed in accordance with the ethical standards laid down in the 1964 Declaration of Helsinki

Source of funding

This article was supported by Baskent University (KA19/303) Author contribution

EC: Conception and design of the study, analysis and interpretation of data, drafting the manuscript, revising the manuscript critically for important intellectual content, Approval of the version of the manuscript to be published.

EZC:Acquisition of data, revising the manuscript critically for important intellectual content, approval of the version of the manuscript to be published.

\section{References}

1. Allameh T, Afsharmoghadam N. Management of atypical squamous cell on cervical cytology. Iran J Gynecol Oncol, 2009;2,43-53

2. American Cancer Society. Cancer Facts and Figures 2006. Atlanta, Georgia, USA: American Cancer Society;2006.

3. Kripke C. Pap smear vs. HPV screening test for cervical cancer. Am Fam Physician. 2008;77(12):1740-42

4. Bidus MA, Elkas JC. Cervical and Vaginal Cancer. In: Berek JS, editors. Berek \& Novak's Gynecology. 2007; $14^{\text {th }}$ ed. Philadelphia: Williams and Wilkins. 1404-56

5. Verhoef VM, Heideman DA, van Kemenade FJ, Rozendaal L, Bosgraaf RP, Hesselink AT, et al. Methylation marker analysis and HPV16/18 genotyping in high-risk HPV positive self-sam- pled specimens to identify women with high grade CIN or cervical cancer. Gynecol Oncol. 2014;135(1):58-63. doi: 10.1016/j. ygyno.2014.08.003

6. Anttila A, Ronco G, Clifford G, Bray F, Hakama M, Arbyn M, et al. Cervical Cancer Screening Programmes and policies in 18 European countries. Br J Cancer. 2004; 91(5):935-41. doi: 10.1038/sj.bjc.6602069

7. Agency for Healthcare Research and Quality. Guide to clinical preventive services, 2008. Recommendations of the U.S. Preventive Services Task Force. [Online] 2009 [Cited 2013 May20). Available from: URL: http://www. pacificcancer.org/pacp-resources/key-cancer-publications/Guide-to-Clinical-Preventive- Services.pdf

8. Massad LS, Jeronimo J, Hormuzd AK, Schiffman M. The accuracy of colposcopic grading for detection of high grade cervical intraepithelial neoplasia. J Low Genital Tract Dis. 2009;13(3):137-44. doi: 10.1097/LGT.0b013e $31819308 \mathrm{~d} 4$.

9. Kyrgiou M, Koliopoulos G, Martin-Hirsch P, Kehoe S, Flannelly G, Mitrou S, et al. Management of minor cervical cytological abnormalities: a systematic review and a metaanalysis of the literature. Cancer Treat Rev. 2007;33 (6):514-20. doi: 10.1016/j.ctrv.2007.05.002.

10. Shafi MI, Luesley DM, Jordan JA, Dunn JA, Rollason TP,
Yates M. Randomised trial of immediate versus deferred treatment strategies for the management of minor cervical cytological abnormalities. Br J Obstet Gynaecol. 1997; 104(5):590-4. doi: 10.1111/j.1471-0528.1997. tb11538.x.

11. Sigurdsson K, Sigvaldason H. Longitudinal trends in cervical cytological lesions and the effect of risk factors. A 30-year overview. Acta Obstet Gynecol Scand. 2006;85 (3):350-8. doi: 10.1080/00016340500432465.

12. Turkish Cervical Cancer and Cervical Cytology Research Group. Prevalence of cervical cytological abnormalities in Turkey. Int J Gynaecol Obstet. 2009;106(3):206-9. doi: 10.1016/j.ijgo.2009.04.003.

13. Yalti S, Gürbüz B, Bilgic, R, Cakar Y, Eren S. Evaluation of cytologic screening results of the cervix. Int J Gynecol Cancer. 2005;15(2):292-4. doi: 10.1111/j.1525-1438. 2005.15218.x.

14. Celik C, Gezginc K, Toy H, Findik S, Yilmaz O. A comparison of liquid-based cytology with conventional cytology. Int J Gynecol Obstet. 2008;100(2):163-6. doi: 10 . 1016/j.ijgo.2007.07.023.

15. Arbyn M, Tulunay G, Ozgul N, Yalvac S, Verguts J, Poppe W, et al. European Union support for a Turkish reproductive health project to assess alternative cervical cancer screening methods in Sanliurfa (rural south-east Turkey). Eur J Cancer Prev. 2006;15(6):552-3. doi: 10. 1097/01.cej.0000215615.82885.99.

16. National Cancer Institute, Surveillance Epidemiology and End Results. Available at: http://seer.cancer.gov/statfacts/ $\mathrm{html} /$ cervix.html.

17. Davey DD, Neal MH, Wilbur DC, Colgan TJ, Styer PE, Moddy DR. Bethesda 2001 implementation and reporting rates: 2003 practices of participants in the College of American Pathologists Interlaboratory Comparison Program in Cervicovaginal Cytology. Arch Pathol Lab Med. 2004;128(11):1224-9. doi: 10.1043/1543-2165 (2004) $128<1224$ :BIARRP $>2.0 . C O ; 2$.

18. Ozçelik B, Serin IS, Gokahmetoglu S, Basbug M, Erez R. Human papillomavirus frequency of women at low risk of developing cervical cancer: a preliminary study from a Turkish university hospital. Eur J Gynaecol Oncol. 2003; 24(2):157-9.

19. Inal MM, Kose S, Yildirim Y, Ozdemir Y, Töz E, Ertopçu $\mathrm{K}$, et al. The relationship between human papillomavirus infection and cervical intraepithelial neoplasia in Turkish women. Int J Gynecol Cancer. 2007;17(6):1266-70. doi: 10.1111/j.1525-1438.2007.00944.x.

20. Alwahaibi NY, Sulimi SK, Bai UR. Cytohistological correlation and discrepancy of conventional Papanicolaou smear test with corresponding histopathology: A retrospective study over a 5-year period. East Mediterr Health J. 2015;21(8):579-83. doi: 10.26719/2015.21.8.579.

21. Abali R, Bacanakgıl BH, Celık S, Aras O, Koca P, Boran B. Histopathological correlation of squamous cell abnormalities detected on cervical cytology. Turk Patoloji Derg. 
2011;27(2):144-8. doi: 10.5146/tjpath.2011.01063.

22. Gupta S, Sodhani P. Why is high grade squamous intraepithelial neoplasia under-diagnosed on cytology in a quarter of cases? Analysis of smear characteristics in discrepant cases. Indian J Cancer. 2004;41(3):104-8.

23. Marques JP, Costa LB, Pinto AP, Lima AF, Duarte ME, Barbosa AP, et al. Atypical glandular cells and cervical cancer: Systematic review. Rev Assoc Med Bras (1992). 2011;57(2):234-8. doi: 10.1590/s0104-42302011000200 024.

24. Lee CY, Ng WK. Follow-up study of atypical glandular cells in gynecologic cytology using conventional Pap smears and liquid-based preparations: Impact of the Bethesda System 2001. Acta Cytol. 2008;52(2):159-68. doi: $10.1159 / 000325474$.

25. Westin MC, Derchain SF, Rabelo-Santos SH, AngeloAndrade LA, Sarian LO, Oliveira E, et al. Atypical glandular cells and adenocarcinoma in situ according to the Bethesda 2001 classification: Cytohistological correlation and clinical implications. Eur J Obstet Gynecol Reprod Biol. 2008;139(1):79-85. doi: 10.1016/j.ejogrb.2007.08. 017.

26. Kim SS, Suh DS, Kim KH, Yoon MS, Choi KU. Clinicopathological significance of atypical glandular cells on Pap smear. Obstet Gynecol Sci. 2013;56(2):7683. doi: 10.5468/OGS.2013.56.2.76.
27. Boyraz G, Basaran D, Salman MC, Ibrahimov A, Onder S, Akman $\mathrm{O}$, et al. Histological follow-up in patients with atypical glandular cells on Pap smears. J Cytol. 2017;34(4):203-7. doi: 10.4103/JOC.JOC_209_16.

28. Tam KF, Cheung AN, Liu KL, Ng TY, Pun TC, Chan YM, et al. A retrospective review on atypical glandular cells of undetermined significance (AGUS) using the Bethesda 2001 classification. Gynecol Oncol. 2003;91(3):603-7. doi: 10.1016/j.ygyno.2003.08.029.

29. Sawangsang P, Sae-Teng C, Suprasert P, Srisomboon J, Khunamornpong S, Kietpeerakool C. Clinical significance of atypical glandular cells on Pap smears: Experience from a region with a high incidence of cervical cancer. J Obstet Gynaecol Res. 2011;37(6):496-500. doi: 10.1111/j.1447-0756.2010.01387.x.

30. Zhao C, Florea A, Onisko A, Austin RM. Histologic follow-up results in 662 patients with Pap test findings of atypical glandular cells: Results from a large academic women's hospital laboratory employing sensitive screening methods. Gynecol Oncol. 2009;114(3):383-9. doi: 10.1016/j.ygyno.2009.05.019.

31. DeSimone CP, Day ME, Tovar MM, Dietrich CS 3rd, Eastham ML, Modesitt SC. Rate of pathology from atypical glandular cell Pap tests classified by the Bethesda 2001 nomenclature. Obstet Gynecol. 2006;107(6):128591. doi: 10.1097/01.AOG.0000218705.87329.4a. 